TITLE:

\title{
Nitration of Desoxybenzoin
}

\author{
$\operatorname{AUTHOR}(\mathrm{S})$ :
}

Sugii, Michiyasu; Nakai, Risaburo

\section{CITATION:}

Sugii, Michiyasu ...[et al]. Nitration of Desoxybenzoin. Bulletin of the Institute for Chemical Research, Kyoto University 1958, 35(5-6): 155-155

ISSUE DATE:

1958-03-30

URL:

http://hdl.handle.net/2433/75605

RIGHT: 


\title{
ABBSTRÄTS
}

Effects of leaching conditions on the extraction of chromium were studied. 1. Size of ore, 2. Leaching time, 3. A.mont of $\left(\mathrm{NH}_{4}\right)_{2} \mathrm{Cr}_{2} \mathrm{O}_{7}$ added, 4. Leaching temperature, and 5. Amont of charge.

Summary of Result : Results obtained are summarized in Table 1, which shows the optimum conditions for extraction of chromium.

If the acid concentration was increased up to $60 \%$, insoluble brownish-yellow precipitate was formed in the presence of $\left(\mathrm{HN}_{4}\right)_{2} \mathrm{Cr}_{2} \mathrm{O}_{7}$ in both cases of leaching.

\section{Reaction of n-Hexyl Bromide with Potassium Fluoride in Several Glycols}

\author{
Hisao Kitano and Ken-ichi Fukui
}

(Kodama Laboratory)

J. Chem. Soc. Japan. Ind. Chem. Sec. (Kögyō Kagaku Zasshi), 60, 272 (1957)

Reactions of $n$-hexyl bromide with potassium fluoride in isomeric propanediols and butanediols are studied. $n$-Hexylfluoride is obtained in high yields by the use of such glycols that have two adjacent hydroxy groups in the molecule. Two geometrical isomers of 1,2-cyclohexanediols are used as the solvent. The yield of $n$ hexyl fluoride is ca. $30 \%$ in the trans isomer, whereas it's only $2 \%$ in the cis isomer.

\section{Nitration of Desoxybenzoin}

\author{
Michiyasu Sugr and Risaburo NAKAI \\ (Nakai Laboratory) \\ J. Org. Chem., 22, 288 (1957)
}

The reaction routes of desoxybenzoin with nitric acid $(d=1.30)$ were studied by using $\mathrm{C}^{1+4-t r a c e r}$ technique. By the nitration of desoxybenzoin-carbonly- $\mathrm{C}^{\mathrm{lt}}$ (I) $\left(12.95 \mu \mathrm{c} / \mathrm{m}\right.$.mole) there were obtained $p$-nitrobenzil-carbonyl-C ${ }^{14}$ (II) $(12.92 \mu \mathrm{c} / \mathrm{m}$.mole), benzil-carbonyl-C ${ }^{14}$ (III) $(12.96 \mu \mathrm{c} / \mathrm{m}$.mole), inactive $p$-nitro-benzoic acid (IV) and benzoic acid-carboxyl-C ${ }^{14}(\mathrm{~V})(11.29 \mu \mathrm{c} / \mathrm{m} . \mathrm{mole})$. When treated with alcoholic potassium hydroxide, II decomposed into inactive $p, p^{\prime}$-azoxydibenzoic acid, inactive $p$-nitrobenzoic acid and benzoic acid-carboxyl- $\mathrm{C}^{14}(12.96 \mu \mathrm{c} / \mathrm{m}$.mole). The se facts indicate that the nitration occurs at the para position to the methylene group of $I$.

The non-labeled specimens of $p$-nitrodesoxybenzoin, $p$-nitrobenzil, and benzil were treated with the nitric acid, respectively. $p$-Nitrodesoxybenzoin gave benzoic acid, $p$-nitrobenzoic acid, and $p$-nitrobenzil. Benzil and $p$-nitrobenzil, however, were resistant to nitration and oxydation, and were recovered without loss. The specific activity of $\mathrm{V}$ is comparatively lower than the theoretical value. These results would lead to the following conclusions. In the action of the nitric acid on desoxybenzoin-carbonyl- $\mathrm{C}^{14}$, the $p$-nitrodesoxybenzoin-carbonyl- $\mathrm{C}^{14}$ is formed as an intermediate, and its methylene group is cxidized to $p$-nitrobenzil-carbonyl- ${ }^{1-4}$. While oxidative disruption of the same intermediate gives benzoic acid-carboxyl- $\mathrm{C}^{14}$ 
and inactive $p$-nitrobenzoic acid. A similar oxidation and oxidative disruption prior to the nitration of desoxybenzoin-carbonyl-C ${ }^{14}$ also take place and give benzilcarbornxl-C $\mathrm{C}^{14}$, benzoic acid-carboxyl- $\mathrm{C}^{14}$ and inactive benzoic acid. The essential reaction routes are shown as follows.

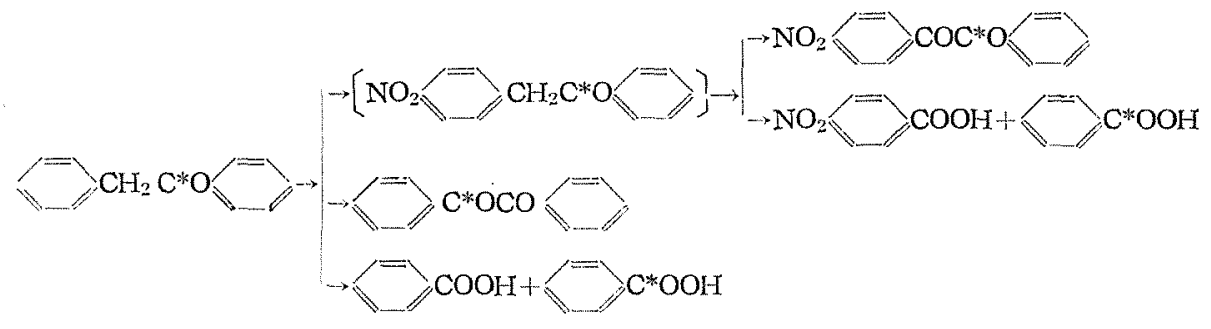

\section{Studies on Condensation Products of Chlorinated Phenols with Chloral. (I)}

The Structure of Condensation Product of 2,4-Dichlorophenol or

2.4-Dichloroanisole with ChIoral

Masayuki Hamada

(Ohno Laboratory)

Scientific Insect Control (Botyu-Kagaku), 22, 231 (1957)

In recent paper, Riemschneider [J.Am. Chem Soc., 76, 4853 (1952)] obtained a compound II, $154^{\circ}$, by methylating condensation product (I) of 2,4-dichlorophenol with chloral, and another compound $\mathrm{V}, \mathrm{mp} .160^{\circ}$, by condensing 2,4-dichloroanisole with chloral. He proposed (1) these two compounds were stereoisomers of 1,1bis-( $2^{\prime}$-methoxy-3',5'-dichloropheny1)-2, 2, 2-trichloroethane resulting from the restricted rotation of benzene rings, and (2) the dichloroethylene compounds III,

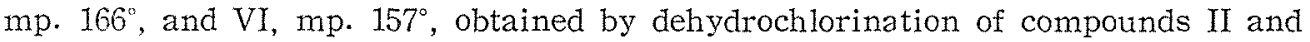
$V$, respectively were also the same type stereoisomers.

This study was undertaken to ascertain the above results and obtained the following conclusion. To a mixture of above 1,1-bis-( $x^{\prime}$-methoxy- $y^{\prime}, z^{\prime}$-dichlorophenyl)-2, 2, 2-trichloroethane (compound II or V) and diethylene glycol was added a concentrated potassium hydroxide solution, and then the mixture was refiuxed a $t 160-70^{\circ}$ for 5 hours. Bis-( $x$-hydroxy-y, $z$-dichlorophenyl)-methane (IV), mp. 167.5 $-68.5^{\circ}$, was obtained from compound II through hydrolysis, decarboxylation and following demethylation. Compound IV was not identical with the corresponding compound VII, mp. 152.5-53.5, obtained from compound V. Compound IV was also prepared by condensing 3, 4-dichlorophenol with paraformaldehyde. Compound IV was then dechlorinated to bis-(2-hydroxyphenyl)-methane, mp. 117-18, with sodium in liquid ammonia. From the above, it was confirmed that the structure of compound II is 1,1-bis-( $2^{\prime}$-methoxy-3', 5'-dichlorophenyl)-2, 2, 2-trichloroethane which was indentical with the structure proposed by Riemschneider.

On the other hand, a compound, mp. $96-97^{\circ}$, which was obtained by the same procedure from compound VII, was identical with bis-(3-hydroxyphenyl)-methane 